\title{
Mudanças na formação e no trabalho de enfermagem: uma perspectiva da educação popular e de saúde
}

\author{
Changes in work and nursing education a perspective of popular and health education
}

Cambios en la educación y trabajo de de enfermería: una perspectiva de la educación popular y de salud

\author{
Helena Maria Scherlowski Leal David', Sonia Acioli' \\ 'Universidade do Estado do Rio de Janeiro. Departamento de Enfermagem e Saúde Pública. \\ Programa de Pós-Graduação em Enfermagem. Rio de Janeiro, RI
}

Submissão: $12 / 12 / 2008$

Aprovação: 05/01/2010

\section{RESUMO}

Trata-se de uma discussão sobre a relação entre os pressupostos da educação popular e saúde e o trabalho e a formação em enfermagem. O texto possui três partes: apresentação do campo da educação popular, com breve histórico e demarcação de alguns pressupostos teórico-metodológicos; discussão dos desafios pedagógicos no trabalho e na formação, com base na proposta pedagógica desenvolvida na FENF/UERJ; e reflexão sobre a potencialidade da inserção de aspectos teórico-metodológicos da educação popular nos currículos de graduação em Enfermagem para o fortalecimento da perspectiva crítico-reflexiva na formação, para dar respostas aos desafios da realidade sanitária, e para o reconhecimento da dimensão pedagógica no trabalho de enfermagem, com vistas ao avanço democrático do Sistema Único de Saúde.

Descritores: Educação em saúde; Educação em enfermagem; Trabalho.

ABSTRACT

This paper discusses the relationship between popular health education presuppositions and nursing education and work. It is divided into three parts: a presentation of Popular Education end Health field, with a brief historic, focusing some theoretical and methodological principles; discussion on pedagogic challenges related to nursing work and education, based on the curriculum of Faculty of Nursing State University of Rio de Janeiro; and reflection about the potentiality of the insertion of theoretical-methodological elements of popular education and health field in nursing undergraduate curriculum as a way of supporting a critical-reflexive perspective in education, giving answers to health reality challenges, and to fortify pedagogic dimension of professional exercise towards democratic advances of Brazilian Health Care System.

Key words: Health education; Education, nursing; Work.

\section{RESUMEN}

Este artículo discute acerca de la relación entre presupuestos de la educación popular y salud y el trabajo y la formación en enfermería. El texto tiene tres partes: presentación del campo de la educación popular, com breve histórico de la marcación de algunos presupuestos teórico-metodológicos; discusión de los desafíos pedagógicos en el trabajo e en la formación con basis el la propuestapedagógica desarrollada en la FEN/UERJ; y reflexión sobre la potencialidad de la inserción de aspectos teórico-metodológicos de la educación popular en los curriculuns del grado en enfermería para fortalecimiento de la perspectiva critico-reflexiva en la formación, para tener respouestas a los desafíos de la realida sanitária, y para el fortaliecimiento de la dimensión pedagógica, con vistas a el avance democratico del sistema unico de salud.

Descriptores: Educación en salud; Educación en enfermería; Trabajo. 


\section{INTRODUÇÃO}

O texto discute alguns aspectos teórico-metodológicos Que orientam as práticas de Educação Popular, indicando Que a incorporação desses aspectos à formação profissional do enfermeiro potencializa a construção de experiências inovadoras na formação e contribui para fortalecimento da dimensão pedagógica do trabalho de enfermagem.

Para tal, as autoras discutem aspectos fundamentais do trabalho de enfermagem e partem de sua vivência docente na Faculdade de Enfermagem da Universidade do Estado do Rio de Janeiro - FENF/ UERJ, cujo projeto pedagógico tem como eixo norteador a proposta pedagógica de Paulo Freire, e de suas trajetórias na Rede de Educação Popular e Saúde, espaço de articulação de profissionais de serviços, da academia e representantes dos movimentos sociais para a troca de saberes e experiências educativas crítico-reflexivas.

Assim, buscaremos refletir a interlocução entre os campos da Educação popular, da formação e do trabalho de enfermagem, apontando para a potencialidade da inserção de aspetos teóricometodológicos da Educação Popular nos processos de formação em Enfermagem, e para a importância de se reconhecer a dimensão pedagógica do trabalho de enfermagem no seu cotidiano, para além das tradicionais palestras, grupos e salas de espera.

\section{EDUCAÇÃO POPULAR E SAÚDE: TRAJETÓRIA DE UM CAMPO DE REFLEXÕES E PRÁTICAS}

A Educação Popular possui raízes históricas no Brasil, Que remontam aos movimentos sociais de caráter popular. Floresce, a partir da década de 1960, com as organizações de suporte a lutas populares, sobretudo a luta camponesa, experiências Que coincidiram com as propostas baseadas nos princípios da Medicina Comunitária desenvolvida pelas instituições acadêmicas de formação médica. Também a Enfermagem de Saúde Pública começou a incorporar os novos conceitos e metodologias educativas nesta época.

Fato relevante neste contexto de reorganização das práticas educativas, a Conferência Internacional sobre Cuidados Primários de Saúde, em Alma-Ata, 1978, apontou para a necessidade do desenvolvimento de estratégias capazes de dar conta da diversidade na oferta de recursos, buscando, ao mesmo tempo, certa uniformidade conceitual e metodológica no desenvolvimento das ações de Saúde Pública, incluindo-se as ações educativas.

Algumas análises históricas sobre as práticas educativas em saúde têm sido bastante críticas Quanto ao processo de "domesticação" das classes subalternas decorrentes da visão higienista e das políticas sanitárias desenvolvimentistas da primeira metade do século passado $^{(1-2)}$, justificando a permanência, entre os profissionais de saúde, de um certo "ranço higienista" na sua prática educativa junto às camadas populares.

O conceito de participação comunitária, exposto no documento do Encontro Nacional de Experiências de Educação em Saúde, de $198 \mathrm{I}^{(3)}$, pretende agregar a visão popular sobre os problemas de saúde, a fim de atender às suas necessidades, Quase como uma forma de "corrigir" uma visão unilateral dos serviços, Que teriam deixado de lado o olhar da população ao longo dos anos. Sente-se aQui a influência do pensamento de Paulo Freire, explicitado na necessidade de incluir um olhar diferente sobre o processo educativo junto às classes populares ${ }^{(4)}$.

A relação entre a Educação Popular e a Saúde passa a se constituir, de modo mais claro, a partir das lutas sociais pela saúde como direito no movimento de Reforma Sanitária, Que trouxe para o debate a necessidade de superação das distâncias culturais entre população e profissionais de saúde.

O movimento, composto por profissionais de saúde, da academia e militantes de movimentos e ONGs, organizou-se na Articulação Nacional de Educação Popular em Saúde, criada em 1991 no I Encontro Nacional de Educação Popular em Saúde, realizado em São Paulo. Em 1998, a Articulação passou a denominar-se Rede de Educação Popular e Saúde.

Na conjuntura histórica em Que emerge o movimento social da Educação Popular e Saúde (EPS) dois marcos se destacam, Quais sejam a dificuldade em implementar o projeto democrático de saúde do SUS em um contexto político neoliberal, e a crítica à racionalidade biomédica, em oposição ao princípio da integralidade.

A partir de 2003, em função da reorganização do Ministério da Saúde, Que passou a incorporar um setor voltado para a articulação com os movimentos sociais da área da saúde, estruturou-se a ANEPS - Articulação Nacional de Movimento e Praticas de Educação Popular e Saúde, instancia mediadora Que tem atuado como interlocutora entre os movimentos e junto ao nível governamental nas três esferas de governo.

Vale lembrar Que as influencias históricas Que conformaram a EPS remontam a contextos anteriores à experiência de alfabetização descrita e sistematizada por Paulo Freire, e incluem influências de ideologias como o cristianismo, o humanismo e o socialismo, Que convergem, tendo como eixo o pensamento de Paulo Freire, "numa pedagogia e concepção de mundo centrada no diálogo, na problematização e na ação comum entre profissionais e população"(5).

Especificamente em relação à enfermagem, um marco foi a experiência de capacitação de Auxiliares de Enfermagem no Projeto de parceria entre o Ministério da Saúde e a Organização Pan Americana da Saúde-OPAS que ficou conhecido como Projeto Larga Escala. Baseando-se na Teórica Crítica, o Larga Escala influenciou, nos anos seguintes, muitos projetos de capacitação, treinamento e reforma curricular da enfermagem ${ }^{(6)}$.

A concepção de mundo e do papel social da educação na EPS determina Que as ações se baseiem em princípios tais como a busca do diálogo e da escuta do outro; tomar como ponto de partida do processo pedagógico o saber anterior das pessoas, acreditando Que todos têm um conhecimento a partir de suas experiências e vivências, de suas condições concretas de existência; atenção e viabilização de momentos de troca de experiências e construção de conhecimento entre o saber técnico e o saber popular, o que pressupõe Que os diversos saberes são apenas diferentes, e não hierarquizados e que a experiência vale tanto Quanto a teoria.

A construção compartilhada do conhecimento é pensada como uma estratégia metodológica Que considera a experiência cotidiana dos atores envolvidos e tem por finalidade a conquista, pelos indivíduos e grupos populares, de maior poder e intervenção nas relações sociais Que interferem na Qualidade de suas vidas”(7).

Mais Que propor uma metodologia educativa, este conceito remete a um Questionamento sobre o papel da ciência e do 
conhecimento científico frente às necessidades e condições desiguais de vida dos grupos populares, cuja lógica de conhecimento do mundo parte do Que se convencionou denominar senso comum.

Os processos de comunicação e produção de idéias da Rede de Educação Popular e Saúde e da ANEPS podem ser descritos em termos de uma "Sociedade em Rede", cujas características são a fluidez, a mobilidade, a mutabilidade e a instauração de laços incertos, em renovação permanente ${ }^{(5)}$. No entanto, se por um lado, o estabelecimento de relações em rede amplia sua capilaridade de ação nos diversos espaços sociais, por outro, a fragilidade destas relações e sua intensa mutabilidade criam algumas dificuldades Quando os participantes tentam inserir este tipo de discussão ou levar adiante projetos pautados pela EPS em suas instituições de saúde ou de ensino. Verificou-se, por exemplo, entre enfermeiros, Que a busca de um "agir educativo" transformador fica restrita, na sua maioria, a práticas e processo individuais, voluntaristas, não organizados coletivamente, muito menos institucionalmente.

Os desdobramentos de se trabalhar educativamente a partir das necessidades e desejos da população demandaram o desenvolvimento de uma sensibilidade especial para com as formas de construção dos saberes sobre saúde, aí se incluindo as experiências com a arte popular, os projetos voltados para lutas na perspectiva de gênero e sexualidade, e inclusão de temas como espiritualidade e religiosidade popular, Que são eixos importantes no desenvolvimento das práticas educativas atuais.

\section{A DIMENSÃO EDUCATIVA DO TRABALHO DE ENFERMAGEM: ADICIONAR OU RECONHECER?}

O profissional enfermeiro pode ser considerado como um dos sustentáculos do projeto do SUS, com destaque para sua atuação no campo das práticas, da docência e da pesquisa em Saúde Pública e Saúde Coletiva.

A profissionalização é analisada na perspectiva da constituição de sujeitos profissionais, como coletivo Que domina um saber técnico-científico específico, normalizado, legitimado do ponto de vista social e juridicamente sancionado, definido a priori, com delimitações mais ou menos claras a respeito do Que o enfermeiro deve e pode fazer, numa concepção carregada de abstração e generalização ${ }^{(8)}$.

Desde uma perspectiva marxista, não se pode desvincular o trabalho das reais e concretas condições de produção e reprodução da existência. Num sentido teleológico, o Que o trabalhador busca, como objetivo, já se expressa idealmente, em sua imaginação, desde o início; mas o resultado final dependerá também das condições concretas de produção do trabalho ${ }^{(9)}$.

A dimensão educativa foi sempre enfatizada no trabalho de enfermagem - ao nosso ver mais Que em outras profissões. Mesmo reconhecendo-se o enfermeiro como educador, a ação educativa tende a ser vista mais como uma ação técnica componente ou adicional ao conjunto de práticas profissionais, em lugar de uma dimensão inerente à prática profissional. Com frequência, esta dimensão é referida como mais uma responsabilidade ou tarefa do enfermeiro a ser incorporada ao processo de trabalho, e tende a reproduzir a racionalidade biomédica hegemônica ${ }^{(8)}$.

A marca do trabalho de saúde é a relação entre sujeitos profissionais e usuários dos serviços. Mehry ${ }^{(10)}$,situa-o como produção em ato, retomando a categoria marxista de trabalho vivo. No trabalho de enfermagem, a ação Que o produz, e o produto final não se separam ${ }^{(1)}$. O espaço do cuidado é este espaço de intersecção, de produção de intersubjetividade, onde o trabalho vivo se dá, e a dimensão educativa permeia este espaço, não se constituindo em dimensão adicional ou externa a ele.

A assimetria na relação entre profissionais e usuários é uma das preocupações Que a EPS traz ${ }^{(4,12)}$, Questionando o fato de Que, nesta relação, é o profissional de saúde Que pauta, coordena e controla a relação pedagógica. Na relação com o paciente ou a coletividade, o enfermeiro é aquele que tem algo a dizer sobre a saúde do outro, discurso socialmente legitimado pela profissão.

Esta assimetria é internalizada e naturalizada no cotidiano do trabalho de enfermagem. O enfermeiro não reconhece a responsabilidade e potencialidade pedagógica do seu trabalho. Pode-se afirmar Que esta alienação, além de comprometer a autonomia do trabalhador, é um elemento capaz de aprofundar mais ainda a assimetria na relação com os usuários. Além disso, é marcante a influencia da lógica taylorista na organização do trabalho de enfermagem, e esta lógica se estende às ações educativas, dificultando a superação da alienação no trabalho(11).

Uma concepção ampliada de educação como mediação social devolve às práticas educativas seu sentido histórico. Esta ressignificação é o Que, por sua vez, permite aos sujeitos reconhecerem o cotidiano como espaço de mediação possível entre o individual-particular e o genérico-histórico ${ }^{(13)}$. Neste sentido, é ferramenta Que amplia a autonomia dos profissionais de saúde como, em cada relação com o usuário, o único responsável pela maneira como se dará o espaço interseçor ${ }^{(10)}$.

Acioli ${ }^{(13)}$ debate o conceito de prática relacionando-o ao de práxis, de modo a facilitar o seu uso como ferramentas para a reflexão. De especial interesse para a presente discussão é o conceito de práxis, como dimensão Que engloba tanto a ação objetiva do homem Quanto suas produções subjetivas, articulando ações e intenções, como superação da alienação.

No sentido proposto por Bourdieu, as práticas e suas representações são estruturadas a partir do habitus. As práticas são ainda fruto de uma série de condições relacionadas ao contexto social, político, econômico e a aspectos da ordem do desejo e da conveniência dos grupos envolvidos. Enquanto produto de uma relação dialética, a prática é expressão da relação entre as condições sociais de produção do habitus e as condições do exercício desse habitus $^{(14)}$.

Consideramos a EPS como campo de idéias relevantes para o fazer da Enfermagem, uma vez Que a ação pedagógica crítica permite ao trabalhador, ao mesmo tempo em Que se torna mais sensível ao sofrimento do outro, avançar numa análise mais aprofundada sobre as relações entre condições e modos de viver e a produção da saúde, para além dos processos biológicos imediatos. Ao buscar uma prática educadora transformadora, o enfermeiro transformase, ao mesmo tempo, como trabalhador, pela ampliação de sua consciência crítica sobre seu próprio processo de trabalho e como educador. Esta subjetivação do trabalho permite-lhe ressignificar sua prática, para além das normas e rotinas impostas pelo trabalho prescrito.

Defendemos, aqui, Que a dimensão educativa possa ser reconhecida como práxis e como atitude educativa, uma 
responsabilidade inerente ao processo de trabalho de enfermagem. Não se trata de propor o desenvolvimento de ações educativas como atividade ou procedimento específico, e sim de reconhecer o potencial pedagógico do trabalho de enfermagem como um todo. Nesta perspectiva, retoma-se uma concepção integradora a respeito do trabalho como prática social.

\section{A POTENCIALIDADE DAS EXPERIÊNCIAS CURRICULARES INFLUENCIADAS PELA EDUCAÇÃO POPULAR E SAÚDE}

A partir da discussão sobre alguns aspectos fundamentais do trabalho de enfermagem, interessou-nos estender o debate para as situações relacionadas à formação profissional, entendendo Que formação e trabalho são dimensões distintas, mas profundamente imbricadas. Baseamos-nos na experiência pedagógica da Faculdade de Enfermagem da Universidade do Estado do Rio de Janeiro (FENF/ UERJ) para destacar algumas Questões sobre a relação entre EPS e a formação do enfermeiro.

O processo de mudança na FENF/UER/ iniciou-se a partir da percepção do corpo docente e discente acerca da necessidade de preparar profissionais cuja atuação pudesse estar mais voltada para os fatores Que conformam a realidade do nosso país, ou seja, um enfermeiro Que pudesse articular dinamicamente ensino - trabalho - comunidade, teoria e prática ${ }^{(15)}$.

Essa percepção traduziu-se em vontade política de mudança a Qual se articulou ao movimento nacional de reforma curricular Que culminou com a elaboração do novo Currículo Mínimo para Formação do Enfermeiro, publicado na Portaria MEC/1721 de 16/12/94.

No âmbito da Faculdade de Enfermagem, acordou-se como princípio Que as propostas deveriam estar pautadas nas diretrizes da Organização do Sistema Único de Saúde, e na defesa da cidadania da população brasileira. Em dezembro de 1994 a Faculdade optou por uma reforma curricular Que rompeu radicalmente com o modelo anterior, dando então origem ao currículo integrado. Mudou-se o paradigma pedagógico, adotandose a Teoria Crítica da Educação como referencial, e incluindo metodologias pedagógicas na linha da Problematização. Ainda Que no Projeto Político Pedagógico não esteja explicitada a aproximação com a Educação Popular, este se aproxima, em termos conceituais e práticos, desta perspectiva.

Transforma-se a reflexão acerca do eixo condutor da compreensão sobre o processo saúde-doença, partindo agora da compreensão do próprio adoecimento eneuanto um processo de complexas determinações sociais, econômicas, políticas e biológicas, estreitamente relacionadas com a Qualidade de vida das populações.

Entendemos, ainda, Que o currículo também é composto por vivências e projetos Que direta e indiretamente reforçam suas bases teórico-metodológicas. O desenvolvimento de ações extensionistas junto a grupos sociais populares em determinadas localidades no município do Rio de Janeiro tem sido uma experiência importante para aproximar docentes/estudantes/profissionais de saúde dos vários contextos sociais, culturais e econômicos existentes, facilitando a possibilidade de diálogo e a troca de saberes na perspectiva da educação popular.

Os projetos rompem com o antigo paradigma assistencialista associado à prática extensionista, desenvolvendo-se de modo articulado ao ensino, como mediação entre instancias produtoras de saberes sobre saúde, ressaltando a dimensão pedagógica crítica da prática profissional e alertando para o fato de Que a produção de conhecimentos pode se dar de modo compartilhado e integrado à dinâmica de vida das comunidades.

Nas aulas teórico-práticas, por meio da problematização, privilegia-se a experiência do aluno para a sistematização do conhecimento e teorização. Como um exemplo, podemos citar o desenvolvimento das aulas sobre políticas de saúde, nas Quais se incorpora a vivência do estudante sobre o Que significa ser atendido no serviço público de saúde, criando uma atividade Que implica em buscar algum atendimento na rede, recuperando, posteriormente, por meio da sistematização, uma vivencia concreta de sentidos, observações e reflexões críticas sobre o Sistema Único de Saúde, seus princípios e problemas a serem superados.

A utilização da problematização como método pedagógico é também um recurso para o ensino de epidemiologia e de conteúdos da saúde pública, já Que várias atividades de ensino são realizadas através de aulas teórico-práticas, desde o ingresso na graduação. No internato, por exemplo, objetiva-se consolidar algumas competências básicas para a atuação em enfermagem de saúde pública, por meio da atuação supervisionada em comunidades, na perspectiva de integração dos saberes e habilidades progressivamente construídos nos períodos anteriores. Assim, ao mesmo tempo em Que é capaz de prestar cuidados e orientações básicas a uma gestante por ocasião da visita domiciliar, é também capaz de identificar o perfil epidemiológico da comunidade onde esta reside, estabelecendo a relação entre os níveis dos determinantes e condicionantes das situações de saúde e os modos de viver das pessoas da comunidade.

Acreditamos que a partir desses "pequenos movimentos" que ocorrem no ambiente pedagógico podemos alimentar "grandes movimentos" Que resultem na ampliação da competência técnica, da consciência crítica e da autonomia do futuro profissional. Esperase formar um profissional Que, partindo das diversas situações de realidade encontradas, esteja apto a identificar e intervir sobre determinantes, riscos e danos a saúde, de acordo com as competências definidas para o profissional enfermeiro.

\section{CONSIDERAÇÕES FINAIS}

Como enfermeiras envolvidas na formação profissional no nível de Graduação parece-nos fundamental dar vida ao ensino, fazer com Que os momentos de aprender e de ensinar tenham alegria e sentido, Que incluam todos os sujeitos envolvidos nos processos de ensino-aprendizagem na perspectiva de construção de formas de um conhecimento sensível.

Uma construção coletiva não é uma tarefa fácil, principalmente Quando se trata de um currículo. Há Que se exercitar tolerância, profissionalismo, capacidade para tomar decisões, objetividade, e principalmente coragem para mudar - mudar como professorenfermeiro, mudar como pessoa.

Nossas atividades no campo da EPS têm trazido importantes lições para nossa atuação docente. Torna-se muito claro Que os processos de aprendizagem acontecem na vida e não apenas dentro dos currículos e das instituições formais. Neste sentido, a EPS, por meio dos princípios do diálogo, do respeito à diversidade e da valorização de sujeitos coletivos nos permite avançar numa formação 
profissional voltada para a construção cotidiana do projeto de saúde do SUS.

Há Que reconhecer os limites Que QualQuer estrutura curricular impõe ao aprendizado, estimulando o desenvolvimento de outras vivências, em articulação com as organizações comunitárias e movimentos sociais da área da saúde. A presença de pessoas da Rede de Educação Popular e Saúde e, mais recentemente, a estruturação da ANEPS, têm atuado como elementos impulsionadores de novas vivências, a exemplo do conjunto de encontros de debate sobre temas de EPS, realizados no ano de 2005 , tendo alguns ocorrido dentro da FENF/UERJ, contando com a participação de alunos de graduação, especialização, mestrado e bolsistas de extensão. Também nos encontros e seminários da ANEP-
RJ procuramos estimular a participação discente, entendendo estes espaços de interlocução como elementos potencializadores não apenas das lutas pela con@uista da saúde, mas também da atuação de enfermeiros comprometidos com um projeto coletivo de saúde.

Nós, enfermeiros envolvidos com a EPS, estamos mudando, e fazer esta mudança dentro do desenvolvimento curricular tem sido uma experiência ao mesmo tempo difícil e gratificante. Este tem sido um processo repleto de contradições e um campo de embates políticos, mas também de estreitamento de laços entre a academia, comunidades e movimentos sociais. Esperamos com esta discussão contribuir para os debates sobre a formação e o trabalho de enfermagem, na perspectiva de uma prática profissional comprometida com um projeto social mais amplo de mudança.

\section{REFERÊNCIAS}

1. Costa NR. Lutas urbanas e controle sanitário. Petrópolis: Vozes/ABRASCO; 1985.

2. Merhy EE. A educação e a saúde: visão histórica. In: Ministério da Saúde (BR). Saúde - perspectivas de atuação dos educadores de saúde pública. Série Educação e Saúde. Brasília: Centro de Documentação do Ministério da Saúde; 1984.

3. Ministério da Saúde (BR). Anais do Encontro de Experiências de Educação e Saúde. Brasília: Ministério da Saúde; 1981.

4. David HMSL. Sentir saúde: a religiosidade como categoria metodológica no trabalho de educação em saúde junto às classes populares [tese]. Rio de Janeiro: Escola Nacional de Saúde Pública. Fundação Oswaldo Cruz; 2002.

5. Stotz EN, David HMSL, Wong-Un IA. Educação popular e saúde - trajetória, expressões e desafios de um movimento social. Rev APS 2005; 8(1): 49-60.

6. Castro IL, Santana IP, Nogueira RP. Isabel dos Santos - a arte e a paixão de aprender fazendo. Natal: Observatório RH NESC/UFRN; 2002.

7. Carvalho MAP, Acioli S, Navarro SE. O processo de construção compartilhada do conhecimento - uma experiência de investigação científica do ponto de vista popular. In: Vasconcelos EM, organizador. A saúde nas palavras e nos gestos: reflexões da rede de educação popular e saúde. São Paulo: Hucitec; 200I. p. 101-14.

8. Almeida CC, Rocha SMM. O trabalho de enfermagem. São Paulo: Cortez; 1997.

9. Lessa S. Mundo dos homens: trabalho e ser social. São Paulo: Bomtempo; 2002.

10. Merhy EE. Saúde - a cartografia do trabalho vivo. $2^{\text {a }}$ ed. São Paulo: HUCITEC; 2002.

11. Ribeiro EM, Pires D, Blank VLG. Theoretical review of the work process in health care used to analyze work in the Family Health Program in Brazil. Cad Saúde Pública 2004; 20(2): 438-46.

12. Vasconcelos EM. Educação popular como instrumento de reorientação das estratégias de controle das doenças infecciosas e parasitárias. Cad Saúde Pública 1998; 14(sup 2): 39-58

13. Acioli S. Os sentidos das práticas voltadas para a saúde e doença: maneiras de fazer de grupos da sociedade civil. In: Pinheiro R, Mattos RA, organizadores. Os sentidos da integralidade na atenção e no cuidado à saúde. Rio de Janeiro: UERJ/ IMS/ABRASCO; 2001.

14. Bourdieu P. Questões de sociologia. Rio de Janeiro: Editora Marco Zero Ltda; 1983.

15. Universidade do Estado do Rio de Ianeiro. Projeto Político Pedagógico do Curso de Graduação em Enfermagem. Rio de Janeiro: Faculdade de Enfermagem; 2003 